\section{Evaluation of Interspecific Hybrids between Lagerstroemia indica and $L$. speciosa}

\author{
Cecil Pounders ${ }^{1,3}$, Tim Rinehart ${ }^{2}$, and Hamidou Sakhanokho ${ }^{2}$ \\ Southern Horticultural Laboratory, Agricultural Research Service, United \\ States Department of Agriculture, P.O. Box 287, 810 Hwy 26 W, Poplarville, \\ MS 39470
}

Additional index words. sterility, SSR markers, 'Princess' crape myrtle, 'Monia' crape myrtle, pollen fertility

\begin{abstract}
Production of viable interspecific seedlings from a cross between Lagerstroemia indica L. 'Tonto' $\times$ L. speciosa $($ L.) Pers. was confirmed by comparison of morphological traits and genetic markers. Traits such as plant height and width showed marked variation within the seedling population whereas variation in other traits such as flower size and color was very limited. Seedlings were found to be functionally sterile as either male or female parents. Observed sterility prevents the maximum introgression of important complex traits such as cold hardiness by sib mating or backcrossing into clones derived from this parental combination. 'Princess' was confirmed to be a sterile hybrid of $L$. indica and $L$. speciosa whereas 'Monia' was indicated to have $L$. indica in its ancestry but not $L$. speciosa.
\end{abstract}

Most of the 56 (Furtado and Srisuko, 1969) to 80 (Cabrera, 2004) species within the genus Lagerstroemia are tropical plants with little cold hardiness. They generally have small white to lavender flowers with little ornamental appeal and are used commercially, primarily for lumber. Only L. indica, L. fauriei Koehne, L. subcostata Koehne, and L. limii Merr. (L. chekiangensis Cheng) have sufficient cold hardiness to be grown in temperate regions. The two most popular ornamental species are $L$. indica, the Indian crape myrtle, and L. speciosa, the Queen's crape myrtle. The ornamental appeal of the two species is somewhat different, with L. speciosa being more robust in all traits but displaying a more limited range of flower colors (lavender, pink, white) and growth habits than $L$. indica. In the United States, crape myrtles ( $L$. indica and $L$. indica $\times$ $L$. fauriei hybrids) are widely planted in the South as small flowering trees. The use of L. speciosa, which forms a large tree, is limited to southern Florida, coastal California, and Hawaii.

In 1963, a chance interspecific seedling ('Basham's Party Pink') between $L$. fauriei and $L$. indica was discovered in Conroe, TX (Egolf and Andrick, 1978). This discovery, in combination with research at the U.S.

\footnotetext{
Received for publication 12 Feb. 2007. Accepted for publication 16 Mar. 2007.

Mention of trade names of commercial products in the publication is solely for the purpose of providing specific information and does not imply recommendation or endorsement by the U.S. Department of Agriculture.

${ }^{1}$ Research Geneticist.

${ }^{2}$ Research Molecular Geneticist.

${ }^{3}$ To whom reprint requests should be addressed;

e-mail cpounders@msa-stoneville.ars.usda.gov
} was resistant to powdery mildew, served as the impetus for a Lagerstroemia interspecific breeding program. This work resulted in the release of more than 20 interspecific hybrid cultivars (Egolf, 1981a, 1981b, 1986a, 1986b, 1987, 1990; Pooler, 2006a; Pooler and Dix, 1999) that successfully combined the powdery mildew resistance of $L$. fauriei with other desirable horticultural traits from L. indica. A high degree of fertility was apparently maintained throughout initial crosses between the two species and various combinations of progeny. Other interspecific crosses incorporated into the $L$. indica $\times L$. fauriei breeding program include L. subcostata ('Yuma') (Egolf, 1987) and L. limii ('Arapaho', 'Cheyenne') (Pooler, 2006a). Several of the U.S. National Arboretum interspecific releases have also demonstrated increased resistance to Cercospora leaf spot (Hagan et al., 1998), flea beetles (Altica spp.), and Japanese beetle (Popillia japonica Newman) (Pettis et al., 2004).

A combination of complementary traits from $L$. indica and $L$. speciosa would appear to have great potential for expanding genetic diversity, for improving pest resistance, and for introducing novel ornamental traits in commercial cultivars. A review of the list of recognized Lagerstroemia cultivars (Dix, 1999) indicates a long history of crosses between the two species. There are, however, less than 10 listed cultivars that resulted from hybridization of $L$. indica and $L$. speciosa, and only two of these, 'Maiden Blush' and 'Monia', were hybridized in the United States (Dix, 1999). Review of the patent for 'Maiden Blush' (Spring, 1965) indicates the cultivar is a hybrid between $L$. indica and $L$. reginae Roxb. rather than with $L$. speciosa. 'Princess', a cultivar of unknown origin
National Arboretum indicating L. fauriei marketed for more than 40 years by Florida nurseries, appears to be a sterile interspecific cross with L. speciosa.

At least three epithets have been used to designate crosses between $L$. indica and $L$. speciosa. First, Lagerstroemia $\times$ matthewsii Searl is indicated to refer to crape myrtles hybridized by C. Matthews in Queensland, Australia, in the 1880s and offered by Searl \& Sons, Sydney, Australia, circa 1905 (Egolf and Andrick, 1978). Second, Lagerstroemia $\times$ eavesii Eaves (Ali, 1977) refers to a hybrid $(L$. $\times$ matthewsii $\times$ L. indica) produced by S.H. Eaves, Brisbane, Australia, and sold by F. Ferguson \& Son, Hurstville, NSW, Australia, in 1913 and later hybrids sold by Hazlewood Bros., Epping, NSW, Australia, in the 1960s (Dix, 1999). Finally, Lagerstroemia $\times$ lancesteri Hort is reported to be a hybrid between $L$. indica 'Candida' and L. Xmatthewsi (Percy-Lancaster, 1921) marketed by Hobbie \& Co., Calcutta, India, in the 1940s (Dix, 1999). None of the three epithets has been found to be validly published and are illegitimate taxonomically.

Interspecific hybrids between $L$. indica and $L$. speciosa have never been studied in detail. More information on the effects of various mating combinations on fertility and the interchange of traits including pest resistance, cold hardiness, and various ornamental attributes is necessary to optimize Lagerstroemia breeding programs. The first objective of this study was to determine fertility and initial variation in progeny for traits such as plant height, plant width, leaf size, and flower size from controlled crosses between 'Tonto' crape myrtle, descended from both $L$. indica and L. faurii, and L. speciosa. The second objective was to test simple sequence repeat (SSR) markers to verify the interspecific hybrid status of progeny from the controlled mating and to evaluate the parentage of two commercial cultivars reported to have originated from crosses between L. indica and L. speciosa.

\section{Materials and Methods}

Plant materials. The following plant material was used in this study: L. speciosa, 'Tonto', 'Arapaho', 'Monia', 'Princess', 'Rosa Nova', and 'Whit IV'. 'Tonto' is a complex hybrid between $L$. indica and $L$. fauriei (Egolf, 1990), whereas 'Arapaho' is a hybrid with $L$. indica, $L$. fauriei, and $L$. limii in its parentage (Pooler, 2006a). 'Monia' and 'Princess' are reported to have originated from crosses between $L$. indica and $L$. speciosa (Dix, 1999), whereas 'Rosa Nova' and 'Whit IV' are cultivars of $L$. indica.

Pollen of L. speciosa used in 2004 to generate the interspecific seedlings evaluated during this study was collected from lavender-flowered accessions 78500B and $2000378 \mathrm{~A}$ at Montgomery Botanical Center, Miami, FL. Foliage and flower samples of L. speciosa for morphological comparison as well as pollen used in fertility evaluations in 2006 were collected from two lavenderflowered specimens at The Liner Farm, St. 


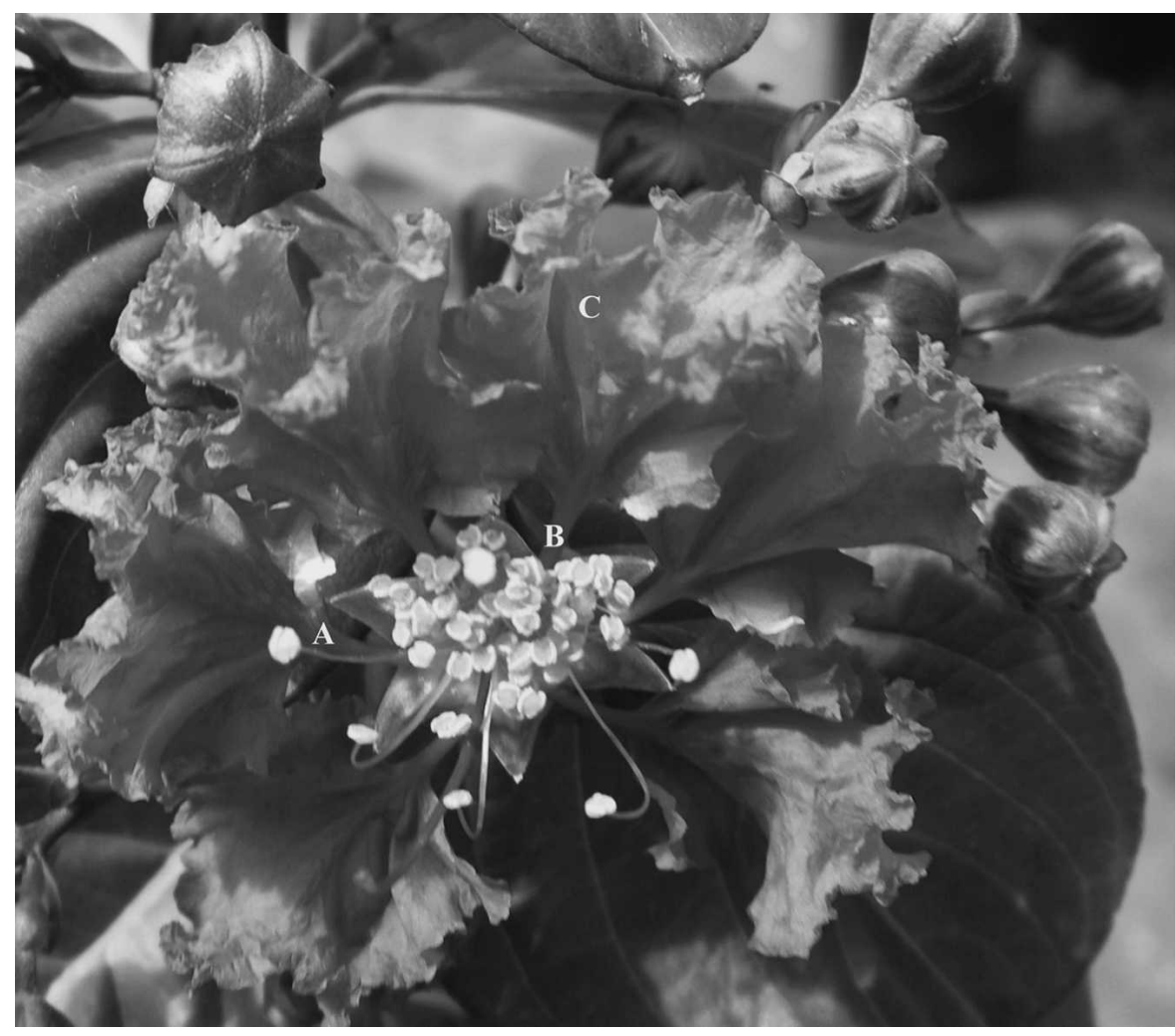

Fig. 1. Flower of 'Tonto' $\times$ Lagerstroemia speciosa seedling showing (A) antesepalous stamen, (B) antepetalous stamens, and (C) petal ruffle typical of $L$. indica.

Table 1. Comparison of eight morphological traits for 'Tonto', Lagerstroemia speciosa, 'Tonto' $\times$ L. speciosa seedlings $(\mathrm{T} \times \mathrm{S})$, 'Princess', and 'Monia'.

\begin{tabular}{lccrrr}
\hline & & \multicolumn{3}{c}{ Lagerstroemia } \\
& Monia & Tonto & $\mathrm{T} \times \mathrm{S}$ & speciosa & Princess \\
\hline Leaf width $(\mathrm{cm})^{\mathrm{zy}}$ & $3.5 \mathrm{~d}$ & $3.0 \mathrm{e}$ & $5.7 \mathrm{~b}$ & $7.8 \mathrm{a}$ & $5.0 \mathrm{c}$ \\
Leaf length $(\mathrm{cm})$ & $4.5 \mathrm{c}$ & $4.3 \mathrm{c}$ & $10.4 \mathrm{~b}$ & $14.7 \mathrm{a}$ & $10.5 \mathrm{~b}$ \\
Flower diameter $(\mathrm{cm})$ & $4.0 \mathrm{~d}$ & $3.8 \mathrm{e}$ & $5.0 \mathrm{c}$ & $6.3 \mathrm{a}$ & $5.5 \mathrm{~b}$ \\
Petal width $(\mathrm{mm})$ & $14 \mathrm{c}$ & $10 \mathrm{~d}$ & $20 \mathrm{~b}$ & $23 \mathrm{a}$ & $20 \mathrm{~b}$ \\
Petal length $(\mathrm{mm})$ & $14 \mathrm{~d}$ & $11 \mathrm{e}$ & $21 \mathrm{c}$ & $24 \mathrm{a}$ & $22 \mathrm{~b}$ \\
Petal crinkle & Yes & Yes & Yes & No & Yes \\
Dimorphic stamens & Yes & Yes & Yes & No & Yes \\
Flower color & Red purple & Red purple & Red purple & Violet G & Purple \\
& $70 \mathrm{~B}$ & $58 \mathrm{~A}$ & $72 \mathrm{~B}$ & $84 \mathrm{C}$ & $76 \mathrm{~B}$ \\
\hline
\end{tabular}

${ }^{\mathrm{z}}$ All measurements reported are the means of 10 random representative specimens.

${ }^{y}$ Means followed by the same symbol within a row are not statistically different based on Duncan's Multiple Range Test (MRT) $(P \leq 0.05)$.

${ }^{\mathrm{x}}$ Color was determined using the Royal Horticultural Society Colour Chart.

$\mathrm{T} \times \mathrm{S}$, 'Tonto' $\times$ L. speciosa seedlings.

Cloud, FL. Plants of 'Rosa Nova' were obtained from Antonio Grassi Nursery, Pistoia, Italy. 'Monia' plants were propagated from plants obtained from Monrovia Nursery, Azusa, CA. 'Tonto' and 'Whit IV' plants were obtained from Byers Nursery, Huntsville, AL. 'Princess' and 'Arapaho' plants were obtained from The Liner Farm.

Seeds from the 2004 interspecific cross were germinated in $5-\mathrm{cm}(220-\mathrm{mL})$ cells in a greenhouse maintained at a minimum temperature of $18{ }^{\circ} \mathrm{C}$ during Mar. 2005. In late May, plants of the clones obtained from the various nurseries and 102 interspecific seedlings were shifted into no. 3 containers $(9 \mathrm{~L})$ in a pine bark substrate top-dressed with $6.6 \mathrm{~kg} \cdot \mathrm{m}^{-3} 19 \mathrm{~N}-2.1 \mathrm{P}-7.4 \mathrm{~K}$ Osmocote Pro fertilizer (Scotts-Sierra Horticultural Products Co., Maryville, OH). Plants were grown in full sun with supplemental irrigation until late October, when the interspecific seedlings and plants of 'Princess' were moved to a greenhouse maintained at a minimum temperature of $2{ }^{\circ} \mathrm{C}$. Named cultivars were exposed to ambient winter conditions. In Mar. 2006, all plants were consolidated back on the container pad, top-dressed again with fertilizer, and grown as in 2005.

Pollinations. Pollen was collected in late June in early morning before anthesis. Anthers were extracted onto white paper and pollen was allowed to dehisce at room temperature $\left(21{ }^{\circ} \mathrm{C}\right)$, then it was stored in vials at $-5{ }^{\circ} \mathrm{C}$. One day before beginning pollinations, seed pods and open flowers were removed from panicles of plants to be used as female parents. These plants were kept in mesh-covered cages throughout pollinations to exclude pollinators. The following morning before anther dehiscence, all newly opened flowers on cultivars in isolation cages were emasculated and flower petals removed. Pollen was applied to stigmas using a fine-tip brush. When pollinations for a study were completed, all remaining flower buds were removed. Plants were left in isolation cages for an additional week until pod development was evident or flowers had senesced. The number of seed pods set for a particular cross was counted after 3 weeks, divided by the number of attempted pollinations, then multiplied by 100 to determine the percentage of pod set.

Pollen staining. Five flowering 'Tonto' $x$ $L$. speciosa seedlings were randomly selected to study pollen viability. Three flowers were collected from the seedlings and from plants of 'Tonto,' 'Princess', and 'Monia'. Flowers of the seedlings and three cultivars had dimorphic stamens (antepetalous and antesepalous) (Kim et al., 1994) that were extracted separately for staining. Freshly dehisced pollen was placed on a microscope slide in a drop of $1 \%$ acetocarmine stain and covered with a coverslip. The slide was heated for $15 \mathrm{~s}$ over steam. Specimens were examined using a light microscope, and pollen was scored as stained (viable) or unstained (nonviable). Three fields of 100 grains each were counted, and the percentage of stainable pollen was calculated for each flower and stamen type. Frozen samples of pollen from the monomorphic stamens of L. speciosa were also evaluated using this procedure.

Simple sequence repeat development and sample processing. Enriched libraries were created by Genetic Information Services (Chatsworth, CA) with the microsatellite motifs GA, AAG, ATG, and CAG using 'Tonto' and 'Whit IV' genomic DNA. Sequencing 1152 clones produced 1765 high-quality sequences that assembled into 250 contigs and 445 singletons. Automated analysis identified 502 sequences containing microsatellite regions where primers could be designed. Some sequences contained multiple microsatellites for a total of 684 potential SSR loci.

DNA was extracted from $1-\mathrm{cm}^{2}$ pieces of fresh leaf tissue using the Qiagen Plant Mini Kit (Qiagen, Valencia, CA) and quantified using a NanoDrop Spectrophotometer (Nanodrop Technologies, Wilmington, DE). Simple sequence repeat amplification was performed using a modified 3-primer protocol (Rinehart et al., 2006). Fluorescencelabeled polymerase chain reaction (PCR) fragments were visualized by automated capillary gel electrophoresis on an $\mathrm{ABI} 3100$ Avant using ROX-500 size standard (Applied Biosystems, Foster City, CA). GeneMapper version 3.7 was used to recognize and size peaks (ABI, Foster City, CA). 
Data analysis. Initial testing of 103 primer pairs, using a modified M13-tailed method, against 'Tonto' and L. speciosa resulted in 43 polymorphic loci. Of these, 15 trinucleotide SSRs were used to verify hybrids. Data were compiled for the seven taxa (L. speciosa, 'Tonto', 'Princess', 'Monia', and three 'Tonto' $\times$ L. speciosa seedlings) and analyzed for shared allele frequencies. All alleles were represented as diploid. Populations version 1.2.28 was used for phenetic analyses (Langella, 2002). Genetic distances between individual samples were calculated using allele sharing distance to create a distance matrix (Jin and Chakraborty, 1994; Stephens et al., 1992). Principle coordinates analysis (PCoA) plots were based on the allele sharing distance matrix, which included missing data as null alleles. Principle coordinates analysis was performed using NTSys software (version

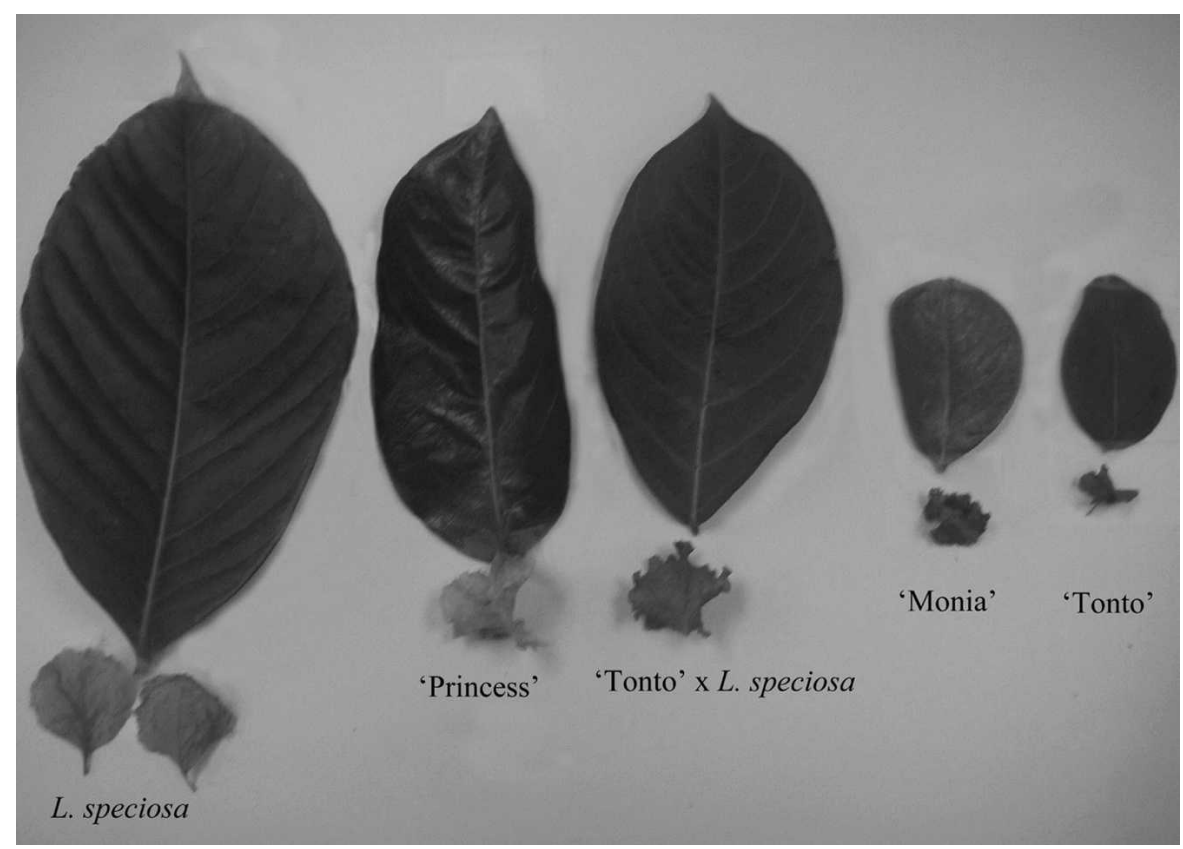

Fig. 2. Visual comparison of leaf and petal size between Lagerstroemia speciosa, 'Princess', a 'Tonto' $\times$ L. speciosa seedling, 'Monia', and 'Tonto'.
1.70; Exeter Software, Setauket, NY). Computation of means, sEs, coefficients of variation, analysis of variation, and mean separations were performed with SAS 9.1 (SAS, Cary, NC).

\section{Results and Discussion}

Initial pollinations between 'Tonto' and L. speciosa generated 102 seedlings. Plant growth of the seedlings was vigorous, with a mean height of $124 \mathrm{~cm}$ and width of $88.2 \mathrm{~cm}$ after 2 years growth in no. 3 nursery containers. Coefficients of variation for the two traits were $35.2 \%$ and $27.4 \%$ respectively. During the first summer, $10 \%$ of the seedlings flowered, with flowering increasing to $39 \%$ during the second summer. Under similar conditions, seedlings grown from the $L$. speciosa parents as breeding stock have not flowered in 5 years. All flowering seedlings had deep-purple flowers (Red Purple 72B by Royal Horticultural Colour Chart. 2001. Royal Horticultural Society, London). Flowers had the petal ruffle and dimorphic stamens characteristic of 'Tonto' and L. indica (Fig. 1). Leaf length, leaf width, flower diameter, petal width, and petal length were all intermediate between the parents (Table 1) (Fig. 2). Characterization of the same traits for 'Princess' and 'Monia' found 'Princess' was most similar to the interspecific seedling population, with the exception of having lavender-pink (Purple 76B) flowers. 'Monia' morphological traits were intermediate between 'Tonto' and the seedling population.

Three random $F_{1}$ plants were chosen for genetic characterization using SSR markers (Table 2). Allele size sharing between progeny and parents confirms that plants are interspecific hybrids between 'Tonto' and $L$. speciosa (Table 3). With the exception of CRAPE165_166 locus in hybrid \#3, all loci are represented by one maternal and one paternal allele. The lack of maternal, or 'Tonto', allele for this sample is likely the result of failure during PCR amplification. Average genetic similarity between the three interspecific hybrids was $\approx 90 \%$, whereas 'Tonto' and L. speciosa are only $\approx 10 \%$ similar. 'Princess' and 'Monia' were also tested with the same SSR markers (Table 2). Thirteen of the 15 loci for 'Princess' contain one allele size corresponding to $L$. speciosa, suggesting it is an interspecific hybrid between $L$. speciosa and $L$. indica. In contrast, 'Monia' is missing data for one locus, but none of the other 14 loci contain allele sizes observed in the $L$. speciosa sample. This result casts doubt on $L$. speciosa being involved in the parentage of 'Monia'. The PCoA plot shows 'Monia' and 'Tonto' separate from all other samples, and 'Princess' and the three interspecific hybrids intermingled and intermediate to $L$. speciosa and L. indica samples (Fig. 3). 'Tonto' and 'Princess' share 62\% genetic similarity, which is comparable with the similarity between 'Tonto' and 'Monia' at 68\%. However, the average genetic similarity between 'Princess' and the $\mathrm{F}_{1}$ hybrids is $86 \%$ whereas

Table 2. Simple sequence repeat loci used to verify interspecific hybrid status.

\begin{tabular}{|c|c|c|c|c|}
\hline Locus & $\begin{array}{c}\text { GenBank accession } \\
\text { no. }\end{array}$ & Repeat motif & Left primer & Right primer \\
\hline CRAPE17_18 & EF143816 & $(\mathrm{GAA}) 5$ & GAGAAGAAGATCTCCAAGGACGG & СТTCCTTGCTCGAGATACCAATGT \\
\hline CRAPE21_22 & EF143817 & (TCT) 6 & CACATCCACAAAGCTGTCGTAGTC & CTTCGAGAAGGTCTTCATGATGCT \\
\hline CRAPE71_72 & EF143819 & $(\mathrm{GAT}) 7$ & GAGAACTCGAATGGGTGTTTGTCT & TGGGGAAAATGGAGAACAAAGATA \\
\hline CRAPE89_90 & EF143820 & (CTG)4 & GAATAGGATGATTCTCCGGCTTCT & AAAGCACAGAGGCTGAAATTAACG \\
\hline CRAPE99_100 & EF143821 & $(\mathrm{CAG}) 7$ & CGCACGGATCTAAGAAAAGAAGAA & TTATAGAAGCAAACCTCTGCAGCC \\
\hline CRAPE117_118 & EF143824 & $(\mathrm{CAG}) 6$ & GGAGTAATGACTACTTCAGCCCGA & ATTGTCAGAGTACCCATCTGGGAG \\
\hline CRAPE119_120 & EF143825 & $(\mathrm{CAG}) 7$ & GGAGTAATGACTACTTCAGCCCGA & TAGAGTACCCATCTGGGAGACGAA \\
\hline CRAPE143_144 & EF143826 & $(\mathrm{GAA}) 7$ & TGTGTTGTGTTGTGCTCTTTGAGA & GATGGACTAATGGCTGTCCCTAAA \\
\hline CRAPE165_166 & EF143827 & (AGA) 8 & TCCATCAGAACATCAAGATTCCTC & ATGCAAGCTTACCACAACAGGTA \\
\hline CRAPE191_192 & EF143828 & (TCT) 8 & TAGGGTTGGAGTGGAAACAGAAAG & AGAGATCAGATGATGAGGAGGAGG \\
\hline CRAPE205_206 & EF143829 & $(\mathrm{AGA}) 16$ & TTCGTATTTAACTGCCATTGACGA & CGTGATAAGGACCGACTAGCCAT \\
\hline
\end{tabular}

Complete DNA sequence information is available from GenBank (www.ncbi.nlm.nih.gov) under the accession numbers listed. Repeat motif and number of repeat units are listed next to primer sequences. Amplified products ranged from 84 to 157-bp long depending on the locus. 


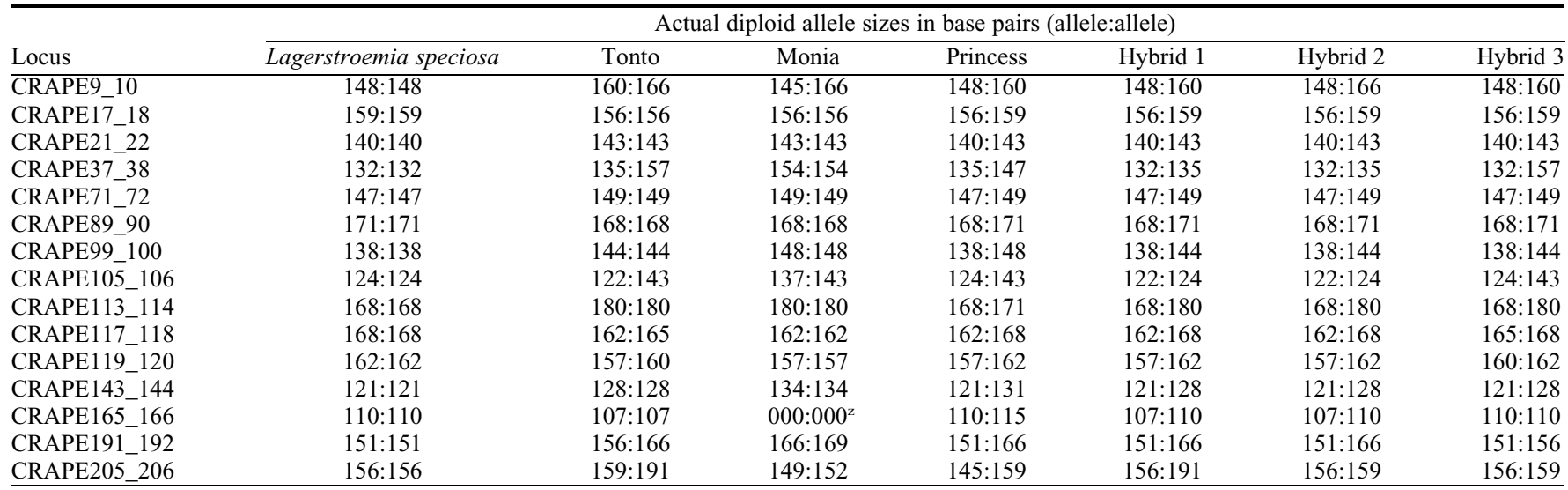

${ }^{\mathrm{Z}}$ Denotes missing data.

Allele sizes reflect the addition of 23 nucleotides that are incorporated during the 3-primer polymerase chain reaction protocol. All samples were assumed to be diploid. As expected from trinucleotide repeats, allele sizes for each locus varied by multiples of $3 \mathrm{bp}$.

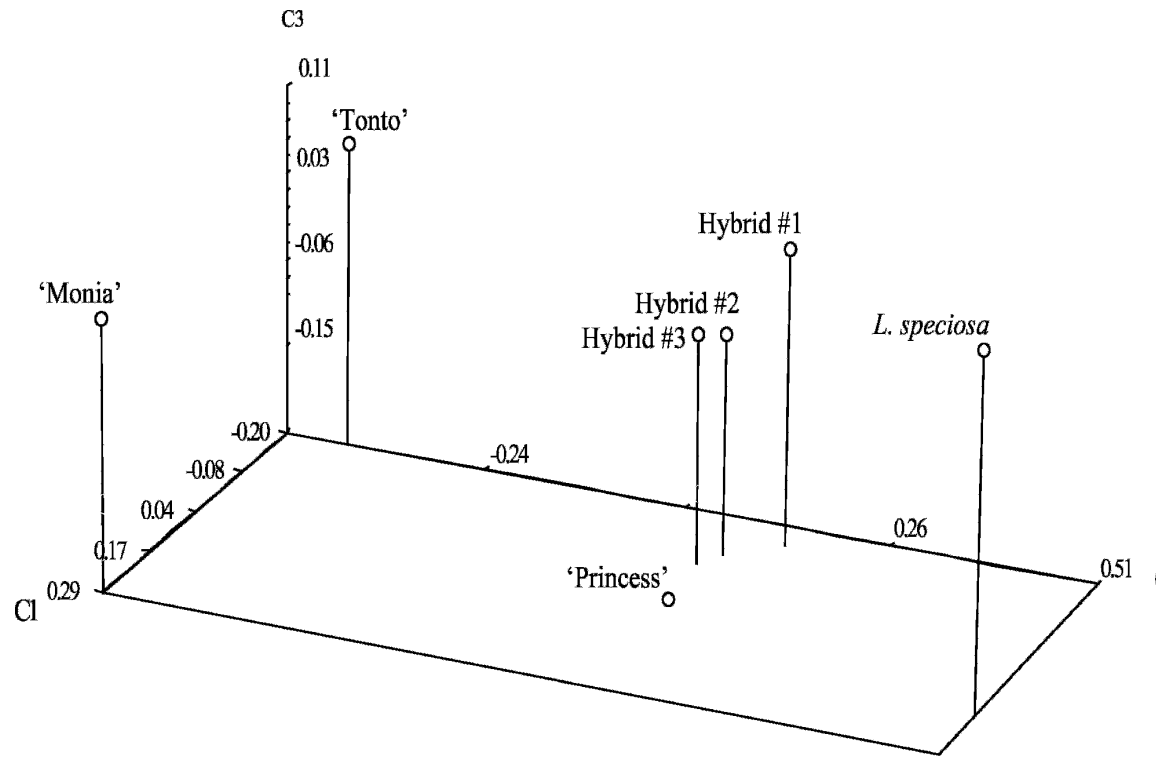

Fig. 3. Principal coordinates analysis of all taxa used to derive a genetic distance matrix. Each axis represents a key variable that explains variation within the data, simplifying the data set to three dimensions but describing as much variation as possible. Samples that cluster together are most likely to share ancestry. Principal coordinates C1, C2, and C3 represent $19 \%, 73 \%$, and $8 \%$ of the variation respectively.

the average genetic similarity between 'Monia' and the $\mathrm{F}_{1}$ hybrids is $57 \%$.

Preliminary evaluation of morphological traits and genetic markers indicates there is ample opportunity to select superior cultivars from the interspecific population. Variation in height and width among the interspecific seedlings was more than twice that reported for a population of open-pollinated L. speciosa seedlings generated from a single mother tree (Jamaludheen et al., 1995). Another trait that appeared to be highly variable in the seedlings was panicle size, which varied in length and floral density. The trait was not measured because development was hampered by plant size and cultural conditions. Variation within the seedlings for other traits of ornamental interest, such as cold hardiness and pest resistance, can also be determined as the population ages and is exposed to more diverse environmental conditions. Flower size and color were both very uniform among the seedlings, offering little or no prospect for selection.

No open-pollinated seed pods were observed on the interspecific seedlings or 'Princess', whereas many pods were present on 'Tonto' and 'Monia' plants grown in the same environment. Examination of pollen after staining with $1 \%$ acetocarmine found no fertile pollen in the samples collected from the 'Tonto' $\times$ L. speciosa seedlings and only $0.2 \%$ stainable pollen from 'Princess' (Table 4). 'Tonto' had $\approx 28 \%$ stainable pollen. Stainable pollen for 'Monia' and L. speciosa was $69.8 \%$ and $97.8 \%$ respectively. A similar study in India found $82.2 \%$ stainable pollen for $L$. indica but only $6.1 \%$ for the interspe- cific clone 'Lancasteri' [L. indica 'Candida' $\times($ L. indica $\times$ L. speciosa $)]$ (Datta and Jena, 1977).

Evaluation of fertility using five randomly selected 'Tonto' $\times$ L. speciosa seedlings or 'Princess' as female parents and 'Arapaho' or L. speciosa as male parents resulted in no pod set (Table 5), whereas remake of the 'Tonto' $\times$ L. speciosa cross resulted in a $13.5 \%$ pod set. Proficient pod set was also recorded when $L$. speciosa was crossed with 'Monia'(47.1\%), 'Arapaho'(34.3\%), and 'Rosa Nova' (30.8\%).

A loss of fertility is often associated with crosses between different species (Poehlman, 1987). Taxonomically, L. indica is grouped in section Sibia, subsection Sibia, whereas L. speciosa is in section Adambea, subsection Adambea (Furtado and Srisuko, 1969). Fertile progeny have resulted from interspecific crosses of L. indica with L. fauriei (Egolf, 1981a), L. subcostata (Egolf, 1987) and L. limii (Pooler, 2006a), all of which are in section Adambea, subsection Microcarpidium. All 'Tonto' $\times$ L. speciosa progeny that have flowered are sterile, as is 'Princess', which we confirmed to be a hybrid between L. indica $\times$ L. speciosa. Sterility may be an asset if superior clones can be selected from the $F_{1}$ population, because it would prevent the possibility of the plants becoming invasive (Pooler, 2006b). However, sterility in the $\mathrm{F}_{1}$ generation prevents the maximum introgression of important complex traits such as cold hardiness, which will severely limit the range of adaptation of selected clones.

The most apparent difference between the two groups of species within section Adambea that have been evaluated in interspecific crosses with $L$. indica is the presence of monomorphic stamens in L. speciosa and dimorphic stamens in L. fauriei, L. subcostata, and L. limii. Differences in stamen arrangement and pollen types within Lagerstroemia have been extensively studied (Kim et al., 1994). Species were categorized into six groups based on pollen size, shape, pseudocolpi, sculpture, and margo. Of the 42 species evaluated, three species including 
Table 4. Percent stainable pollen in nine Lagerstroemia accessions.

\begin{tabular}{|c|c|c|}
\hline Cultivar/hybrid & Pollen type & Stained pollen ${ }^{\mathrm{z}}(\%)$ \\
\hline Lagerstroemia speciosa & Monomorphic & $97.0+2.0$ \\
\hline Monia & Antepetalous & $69.8 \pm 4.5$ \\
\hline Monia & Antesepalous & $91.2 \pm 1.9$ \\
\hline Tonto & Antepetalous & $29.2 \pm 2.1$ \\
\hline Tonto & Antesepalous & $27.3 \pm 2.2$ \\
\hline Princess & Antepetalous & $0.2 \pm 0.1$ \\
\hline Princess & Antesepalous & $0.2 \pm 0.1$ \\
\hline Tonto $\times$ L. speciosa $\# 1$ & Antepetalous & $0.0 \pm 0.0$ \\
\hline Tonto $\times L$. speciosa \#1 & Antesepalous & $0.0 \pm 0.0$ \\
\hline Tonto $\times$ L. speciosa $\# 2$ & Antepetalous & $0.0 \pm 0.0$ \\
\hline Tonto $\times L$. speciosa $\# 2$ & Antesepalous & $0.0 \pm 0.0$ \\
\hline Tonto $\times$ L. speciosa $\# 3$ & Antepetalous & $0.0 \pm 0.0$ \\
\hline Tonto $\times L$. speciosa $\# 3$ & Antesepalous & $0.0 \pm 0.0$ \\
\hline Tonto $\times$ L. speciosa $\# 4$ & Antepetalous & $0.0 \pm 0.0$ \\
\hline Tonto $\times L$. speciosa $\# 4$ & Antesepalous & $0.0 \pm 0.0$ \\
\hline Tonto $\times$ L. speciosa $\# 5$ & Antepetalous & $0.0 \pm 0.0$ \\
\hline Tonto $\times L$. speciosa $\# 5$ & Antesepalous & $0.0 \pm 0.0$ \\
\hline
\end{tabular}

${ }^{\mathrm{z}}$ Mean $\pm \mathrm{SE}$.

Table 5. Comparison of pod set for five crape myrtle cultivars and $F_{1}$ interspecific seedlings.

\begin{tabular}{|c|c|c|c|}
\hline Female & Male & Crosses (no.) & Pod set ${ }^{z}(\%)$ \\
\hline$\overline{\text { Monia }}$ & L. speciosa & 184 & $47.1 \pm 13.9$ \\
\hline Arapaho & L. speciosa & 267 & $34.3 \pm 6.7$ \\
\hline Rosa Nova & L. speciosa & 243 & $30.8 \pm 5.0$ \\
\hline Tonto & L. speciosa & 244 & $13.5 \pm 3.6$ \\
\hline Princess & L. speciosa & 64 & $0 \pm 0.0$ \\
\hline \multicolumn{4}{|l|}{ Tonto $\times$ Lagerstroemia } \\
\hline speciosa \#6 & L. speciosa & 45 & $0 \pm 0.0$ \\
\hline Tonto $\times$ L. speciosa $\# 7$ & L. speciosa & 47 & $0 \pm 0.0$ \\
\hline Tonto $\times$ L. speciosa $\# 8$ & L. speciosa & 35 & $0 \pm 0.0$ \\
\hline Tonto $\times$ L. speciosa $\# 9$ & L. speciosa & 29 & $0 \pm 0.0$ \\
\hline Tonto $\times$ L. speciosa $\# 10$ & L. speciosa & 23 & $0 \pm 0.0$ \\
\hline Princess & Arapaho & 82 & $0 \pm 0.0$ \\
\hline Tonto $\times$ L. speciosa $\# 6$ & Arapaho & 60 & $0 \pm 0.0$ \\
\hline Tonto $\times$ L. speciosa $\# 7$ & Arapaho & 45 & $0 \pm 0.0$ \\
\hline Tonto $\times$ L. speciosa $\# 8$ & Arapaho & 47 & $0 \pm 0.0$ \\
\hline Tonto $\times$ L. speciosa $\# 9$ & Arapaho & 55 & $0 \pm 0.0$ \\
\hline Tonto $\times$ L. speciosa $\# 10$ & Arapaho & 49 & $0 \pm 0.0$ \\
\hline
\end{tabular}

${ }^{\mathrm{z}}$ Mean $\pm \mathrm{SE}$.

L. speciosa were found to have unique pollen and were not assigned to any of the five major groups, but were lumped into a sixth miscellaneous group. Group III included L. subcostata, L. fauriei, and L. limii, whereas L. indica was classified in group IV. Lagerstroemia fauriei pollen was indicated to have the greatest structural similarity with $L$. indica of the species in group III. The six pollen groups may be a better indicator of interspecific combinations most likely to retain fertility than the currently accepted sectional groupings.

Chromosome counts reported for Lagerstroemia species are often confusing. This is partly the result of small chromosome size and dysploidy within genera of the Lythraceae (Graham and Cavalcanti, 2001). Bowden (1945) reports $2 \mathrm{n}=50$ for both $L$. indica and $L$. speciosa, while Guha (1972) reports $2 \mathrm{n}=50$ for $L$. indica and $2 \mathrm{n}=48$ for $L$. speciosa. Meiosis was examined in pollen mother cells of 'Lancasteri', a clone with seed sterility and limited functional pollen that is reported to have resulted from a cross of $L$. indica 'Candida' with $L$. indica $\times L$. speciosa (Ali, 1977; Datta and Jena, 1977). A high frequency of univalents and bivalents with abnormal meiotic behavior was observed, indicating the two genomes involved in the parentage of the hybrid are cytogenetically well differentiated.

'Monia' is reported to be a hybrid between $L$. indica $\times L$. speciosa made by Otto Spring, Okmulgee, OK (Dix, 1999). We have determined this parentage to be incorrect using SSR markers. Although it is possible that repeated backcrossing might bias the allele size variation such that our 15 markers were insufficient to detect the L. speciosa genetic background, it is unlikely given the lack of fertility we documented in the 'Tonto' $\times$ L. speciosa $\mathrm{F}_{1}$ progeny and evidence that 'Monia' is both male and female fertile (Tables 4 and 5). Review of the patent for 'Maiden Blush' (Spring, 1965), another tropical hybrid crape myrtle produced by Spring (1965) and reported as an L. speciosa hybrid by Dix (1999), indicates the cultivar originated from a cross between $L$. indica and $L$. reginae (section Adambea, subsection Adambea) rather than $L$. speciosa. Our results indicate 'Monia' is probably an interspecific hybrid between $L$. indica and another species, but not $L$. speciosa.

In summary, seedling populations can be easily generated by crossing $L$. indica clones with L. speciosa. Data recorded from the 'Tonto' $\times$ L. speciosa progeny display high variation for traits such as plant growth and form, indicating superior cultivars can be selected for such traits from the initial cross. The high level of sterility observed in 'Princess' and the interspecific progeny indicates that breeding programs requiring backcrossing or sib mating to improve traits such as flower size and cold hardiness will be difficult, if not impossible, to execute. The possibility of recovering fertile interspecific seedlings from other combinations with $L$. speciosa is being investigated. The SSR markers tested here should be useful tools for verifying interspecific hybrids and assessing genetic diversity among Lagerstroemia species.

\section{Literature Cited}

Ali, R. 1977. Chromosome numbers in some species of Lagerstroemia. Curr. Sci. 46:579-580.

Bowden, W.M. 1945. A list of chromosome numbers in higher plants I. Acanthaceae to Myrtaceae. Amer. J. Bot. 32:81-92.

Cabrera, R.I. 2004. Evaluating and promoting the cosmopolitan and multipurpose Lagerstroemia. Acta Hort. 630:177-184.

Datta, R.M. and P.K. Jena. 1977. Preliminary meiotic studies in three species of garden Lagerstroemia (L. flos-reginae Retz., L. Lancasteri, a new horticultural variety and $L$. indica Linn. Var Rose Colour). Indian Agriculturist 21:87-89.

Dix, R.L. 1999. Cultivars and names of Lagerstroemia. U.S. National Arboretum. 2 Nov. 2006. <www.usna.usda.gov/Research/Herbarium/ Lagerstroemia/index.html $>$.

Egolf, D.R. 1981a. 'Muskogee' and 'Natchez' Lagerstroemia. HortScience 16:576-577.

Egolf, D.R. 1981b. 'Tuscarora' Lagerstroemia. HortScience 16:788-789.

Egolf, D.R. 1986a. 'Acoma', 'Hopi', 'Pecos', and 'Zuni' Lagerstroemia. HortScience 21:12501252.

Egolf, D.R. 1986b. 'Tuskegee' Lagerstroemia. HortScience 21:1078-1080.

Egolf, D.R. 1987. 'Apalachee', 'Comanche', 'Lipan', 'Osage', 'Sioux', and 'Yuma' Lagerstroemia. HortScience 22:674-677.

Egolf, D.R. 1990. 'Caddo' and 'Tonto' Lagerstroemia. HortScience 25:585-587.

Egolf, D.R. and A.O. Andrick. 1978. The Lagerstroemia handbook/checklist. American Association of Botanical Gardens and Arboreta, Inc., Wilmington, DE.

Furtado, C.X. and M. Srisuko. 1969. A revision of Lagerstroemia L. (Lythraceae). Garden Bul. (Singapore) 24:185-334.

Graham, S.A. and T.B. Cavalcanti. 2001. New chromosome counts in Lythraceae and a review of chromosome numbers in the family. Syst. Bot. 26:445-458.

Guha, S. 1972. Cytotaxonomic studies on the family Lythraceae. Pro. Indian Academy of Science Congress Assoc. 59:344-345.

Hagan, A.K., G.J. Keever, C.H. Gilliam, J.D. Williams, and G. Creech. 1998. Susceptibility of crape myrtle cultivars to powdery mildew and Cercospora leaf spot in Alabama. J. Environ. Hort. 16:143-147.

Jamaludheen, V., K. Gopikumar, and K. Sudhakara. 1995. Variability studies in Lagerstroemia (Lagerstroemia speciosa Pers.). Indian Forester 121:137-142. 
Jin, L. and R. Chakraborty. 1994. Estimation of genetic distance and coefficient of gene diversity from single-probe multilocus DNA fingerprinting data. Mol. Biol. Evol. 11: $120-127$.

Kim, S.C., S. Graham, and A. Graham. 1994. Palynology and pollen dimorphism in the genus Lagerstroemia (Lythraceae). Grana 33:1-20.

Langella, O. 2002. Populations: A free population genetics software. 29 Feb. 2006. <www.pge. cnrs-gif.fr/bioinfo/populations/index.php?lang= en $\&$ doc $=$ populations. $>$

Percy-Lancaster, S. 1921. Lagerstroemia. Proc. J. Agr. Hort. Soc. India 20-21.
Pettis, G.V., D. Boyd, S. Braman, and C. Pounders. 2004. Potential resistance of crape myrtle cultivars to flea beetle (Coleoptera: Chrysomelidae) and Japanese beetle (Coleoptera: Scarabaeidae) damage. J. Econ. Entomol. 97:981-992.

Poehlman, J.M. 1987. Breeding field crops. Van Nostrand Reinhold, New York.

Pooler, M.R. 2006a. 'Arapaho' and 'Cheyenne' Lagerstroemia. HortScience 41:855-856.

Pooler, M.R. 2006b. Crape myrtle: Lagerstroemia indica, p. 428-449. In: N.O. Anderson (ed.). Flower breeding and genetics: Issues, challenges, and opportunities for the 21 st century. Vol. 2. Springer, New York.
Pooler, M.R. and R.L. Dix. 1999. 'Chickasaw', 'Kiowa', and 'Pocomoke' Lagerstroemia. HortScience 34:361-363.

Rinehart, T.A., B.E. Scheffler, and S.M. Reed 2006. Genetic diversity estimates for the genus Hydrangea and development of a molecular key based on SSR. J. Amer. Soc. Hort Sci. 131:787-797.

Spring, O. 1965. Variety of crepe myrtle. U.S. Patent and Trademark Office. PP 2,551.

Stephens, J.C., D.A. Gilbert, N. Yuhki, and S.J. O'Brien. 1992. Estimation of heterozygosity for single-probe multilocus DNA fingerprints. Mol. Biol. Evol. 9:729-743. 